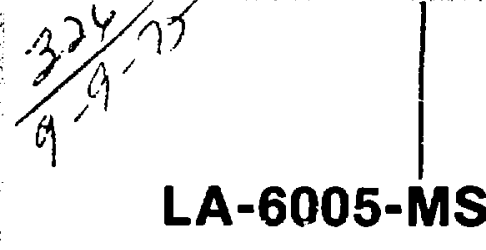

Informal Report

\section{Application of a Drift-Flux Model to Flashing in Straight Pipes}

by

c. W. Hirt

N. C. Romero
UC.78c

Reporting Date: June 1975 Issued: July 1975 
In the interest of prompt distribution, this report was not edited by the Technical Information staff.

Work supported by NRC.RES, Task No. 07559.

Printed in the United States of America. Available from National Technical Information Service

US Department of Commerce

5235 Port Royal Road

Springlield, VA 22151

Price: Printed Copy \$4.00 Microtiche \$2.25

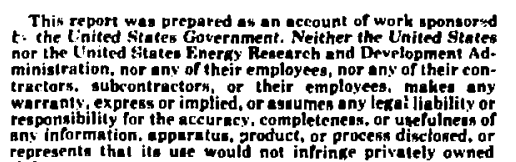

t. the Lnited States Government. Neither the United States ministration nor les of their enearch and Davplopment Adtractars. subcontractors, or their employees, makes any responsibility for the accuracy, completeness, or ugefulnein of ans information. epperstus. product, or process dichoned, or represents.
rikhts. 


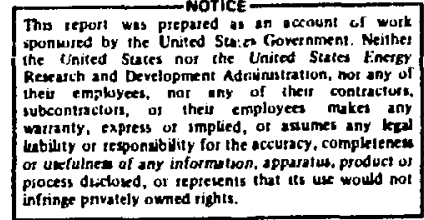

APPLICATION OF A DRIFT-FLUX MODEL TO FLASHING IN STRAIGHT PIPES

by

C. W. Hirt and N. C. Romero

\begin{abstract}
A new computer program, SOLA-JF, has been written to solve the unsteady, two-dimensional equations of motion for a two-phase inixture. The equations solved are based on the drift-flux approximation and include a phase transition model and a general drift velocity calculation. In this report the SOLA-DF code is used for a study of the blowdown of straight pipes initialiy filled with water at high temperature and pressure. Computed results are presented that show the relative importance of phase transition rates, pipe friction, drift velocity magnitude, and other model variations. The computed results are also compared with experimental data.
\end{abstract}

\section{INTROOUCTION}

The data obtained by Edwards et al.' in depressurization experiments in straight pipes has been used as the basis of a standard test problem (Standard Problem Number 1) for evaluation of reactor safety analysis codes. Many of the codes currently in use for evaluation studies have been applied to this problem and their results are reported in Ref. 2.

One objection raised in connection with all of the previously reported results is that they require the selection of certain arbitrary parameters. For example, most of the codes employ a Moody break flow multiplier, which controls the discharge rate of the pipe. Different codes use different values for this multiplier and the value usually chosen is the one that gives the best agreement with experiment. When the break flow multiplier is set to unity, corresponding to no special adjustment, all computed results show a discharge rate well above the measured value (see Ref. 2, Fig. 17).

In an attempt to develop a better two-phase flow predictive capability, we have written a computer code, SOLA-DF, that solves the transient, two-dimensional drift-flux equations ${ }^{3}$ for a two- phase mixture. These equations and the constitutive relations used in SOLA-DF are described in the Appendix. Here we report the results obtained with SULA-DF for the original Eulvards experiment, which employed a 3-ili. pipe and for similar experiment ${ }^{4}$ smploying an $s-i n$, pipe. All results presented here were obtained by treating the pipe interiors as one-dimensinal flow channels and the region outside the pipe end as a two-dimensional flow region. No special constraints are imposed on the flow at the open end of ihe pipe. The full equations are solved so that choking, if it occurs, occurs automatically.

Computed results are presented that show the relative importance of phase transition rates, pipe friction, relative velocity magnitude, and other model variations. Generally speaking, good agreement with the data is obtained with the drift-flux model run nearly in the limit of honogeneous, equilibrium flow; that is, with little or no relative velocity and with a large phase transition rate. This conclusion, however, relies on the use of an initial temperature below that reported for the experiments. Some discussion regarding this is presented in the concluding comments. The computed 
results are most sensitive to the choice of pipe friction and require a rough, rather than smooth, pipe friction loss to achieve good agreement. The results, however, are not sensitive to the magnitude of the pipe roughness in the range believed to be representative of the experimental apparatus. Results are sensitive to the choice of a two-phase pipe friction multiplier as described later, with the best results coming from an annular type multip] ier.

A brief description of the drift-flux model and the numerical solution procedure for the present applications is contained in the next section. Results are presented in Section III and concluding remarks in Section IV.

\section{THE MODEL}

In this section are detailed the special considerations needed to perform the calculations described in Section IIl.

A. The pipe is treated one-dimensionally; thus, in the mean momentum equation we introduce a pipe friction force per unit volume $f_{v i s}$ defined as

$$
f_{v i s}=\frac{-f}{2 D} o_{\ell}^{0} U_{\ell}^{2}(1-\theta)^{2} \varphi_{T P}^{2}
$$

where $D$ is the pipe diameter, $\rho_{l}^{O}$ the microscopic liquid density, $\theta$ the volume fraction occupied by vapor, $U_{\ell}$ the mean axial liquid velocity, and ofp is a multiplier expressing the change in pure liquid friction when both gas and liquid phases are present. The factor $f$ depends on pipe roughness $k / D$ and on Reynolds number Re $=\underline{D U} \underline{v}_{l}$ where $v_{l}$ is the kinematic viscosity of the liquid. An expression for $f$, valid for a wide range of $R e$, is

$$
\frac{1}{\sqrt{f}}=1.74-2 \log _{10}\left(\frac{2 k}{D}+\frac{18.7}{\operatorname{Re} \sqrt{f}}\right) \text {. }
$$

Strictly speaking, the Reynolds number used in $f$ should be defined in terms of some adjusted diameter, velocity, and viscosity representative of the two-phase mixture, but for reasonably large values of Reynolds number $f$ is independent of this refinement.

A roughness of approximately $k / D=10^{-3}$ is typical for structural steel pipes while $k / D \approx$
$2.5 \times 10^{-4}$ is typical for something between structural steel and drawn pipes. The smaller value has been used for all of the reported calculations.

B. The two-phase multiplier ${ }^{\mathrm{TP}}$ can be approximated in several ways.

simple arguments ${ }^{5}$ lead to the conclusion that for homogeneous (and zero slip) flow the multiplier is

$$
\Phi_{T P}^{2}=\frac{\rho}{\rho_{Q}}-\frac{1}{(1-4)^{2}}
$$

so that the pipe friction force per unit volume reduces to

$$
f_{\text {vis }}=\frac{-f}{20} \rho u^{2} \text {. }
$$

As one expects, in the case of homogeneous flow with zero slip, the friction reduces to that for a single fluid with mean density $p$ and velocity $U$.

If we assume annular type flow instead of a homogeneous distribution of phases, the two-phase friction multiplier is

$$
\varphi_{T P}^{2}=\frac{1}{(1-\theta)^{2}}
$$

and the friction force then reduces to

$$
f_{v i s}=\frac{-f}{2 D} \rho U^{2}\left[\frac{\rho}{0} \frac{(1-x)^{2}}{(1-\theta)^{2}}\right]
$$

where $x$ is the flow quality, ${ }_{g} U_{g} / \rho U$. With zeroslip this further reduces to

$$
f_{v i s}=\frac{-f}{2 D} \circ U^{2}\left(p_{\ell}^{o} / 0\right)
$$

which is $\left(\rho_{\ell}^{0} / \rho\right)$ times as large as the homogeneous result.

$$
\text { Chishol } \mathrm{m}^{5} \text { has suggested an alternative form }
$$
for ${ }_{T P}$, which reduces in the zero-slip limit to approximately the homogeneous result. The annular and homogeneous type friction multipliers represent two extreme forms for ${ }^{\Phi} \mathrm{TP}$. in the present study both forms have been tried, with the best agreement with experimental data coming from the annular type 
multiplier. This result, which will be discussed in more detail in Section III, certainly does not imply that the flow is more nearly annular than homogeneous. The terms annular and homogeneous are used here only as convenient labels for different types of two-phase friction multipliers.

C. Edwards et al. ' reported that the diaphragm at the end of their pipe did not break cleanly, but left a ragged edge that reduced the open area of the pipe by approximately 13\%. This effect was included in the calculations by reducing, by $13^{\circ}$, the area open for mass fluxes and the area open for pressure acceleration work.

D. Details of the basic numerical solution procedure will be described in a later report. For present purposes we only remark that considerable use is made of implicit numerical methods. In particular, implicit formulations are included for pressure accelerations, for phase transitions, and for pipe irictions. Furthermore, an iterative method is used to compute relative velocities, since they are defined by non-linear equations. Without implicit formulations for these processes very small time steps would be required and calculations would be too iengthy and expensive for extensive investigations.

E. The finite difference mesh used for most of the present studies consisted of a 2-cell-wide and 45-celi-high arrangement of rectangular cells. The left edge of the mesh is the axis of symmetry, and the pipe wall is simulated by blocking out the lower 40 cells in the second column out from the axis. The top and right sides of the mesh, above the open end of the pipe, were continuative boundaries along which gradients in all flow quantities are set to zero.

The region outside the open end of the pipe is only two cells wide, and is not sufficient to accurately resolve the discharge flow. For most calculations, phase transitions were not computed in this region and relative velocities were set to zero. However, one calculation was repeated with a mesh 5 cells wide outside the pipe exit, which does offer reasonable resolution of the discharge (see Section 1II). In this case, phase transitions were allowed as were relative velocities, so the discharge flow was computed everywhere using the full dynamic equations. The flow computed within the pipe was observed to be nearly identical to that obtained with the simpler boundary conditicn. Therefore, for the present study, the simpler boundary condition was a good approximation. It must be emphasized, however, that in either case no special conditions were imposed on the flow at the pipe exit plane. Except for the above-nentioned simplification, the complete dynamic equations are solved both inside and outside tie pipe. The flow recognizes the pipe exit as that location where radial expansion is permitted. If choking is to occur it will do so automatically in a manner consistent with the basic conservation laws embodied in the governing equations of motion. This treatment of the exit flow is novel. All previous models have used specia? exit flow conditions, such as break flow multipliers, specified pressure drops or Mach numbers that contain adjustable parameters used to improve agreement between model predictions and experimental data.

F. In all cases reported here the initial contents of the pipe consisted of water at a pressure of 70 bars and with a constant temperature of $502.2^{\prime \prime} \mathrm{K}\left(445^{\circ} \mathrm{F}\right)$. This temperature is less than the $515^{\circ} \mathrm{K}$ temperature reported for the experiment, but is an average of the axial profile recommended by ANC fir Standard Problem No. 1. The recommended temperature profile was not used since we believe the use of initial temperatures significantly below those reported by the experimenters (for both the 3in. and o-in. pipis) deserves more investigation (see Section IV).

G. All calculations were performed using a constant time step of $0.1 \mathrm{~ms}$. This time increment could possibly be increased to $0.2 \mathrm{~ms}$, but any larger value would result in a numerical instability caused by material attempting to convect too far across a mesh zone during a time step. All calculations were $5-m i n$ runs on a $\operatorname{CDC}-7600$ computer. Because of different implicit iteration requirements, some calculations ran to the completion time of 600 ws while others only reached times of approximately $370 \mathrm{~ms}$. No attempt was made to extend the slower running calculations to later times since the final run out of the blowdown process would not alter the conclusions reached in the next section. 


\section{RESLILTS OF CALCULATIONS}

The standard calculation of this series, which gives relatively good agreement with experinental data, had the following specifications:

a. The pipe was zoned with 40 mesh zones, each of length $10.24 \mathrm{~cm}$.

b. The initial temperature was a uniform $502.2^{\circ} \mathrm{K}$.

c. The phase transition coefficient was ro $=0.10$.

d. No phase transitions or relative velocities were permitted outside the pipe, and the exit area was reduced by $33 \%$.

e. The pipe friction coefficient was conguted assuming a pipe roughness of $1.83 \times 10^{-3} \mathrm{~cm}$ and the two-phase friction multiplier was of the type often used for annular flow.

f. Interfacial friction was computed assuming a drag coefficient $C_{d}=0.5$ and that approximately 10 bubbles or drops existed per unit volume.

Results of this standard calculation are shown in comparison with the experimental data in figs. ia-j. Locations of the various gauge stations are listed in Table $i$ in centineters from the diapirann. The computed pressure history at each gauge station exhibits a dip immediately after the passage of the initial 70-bar depressurization wave, Figs. 7a-c. The dip reflects the finite phase transition rate used in all calculations. Results at gauge station 7 , located at the closed end of the pipe.

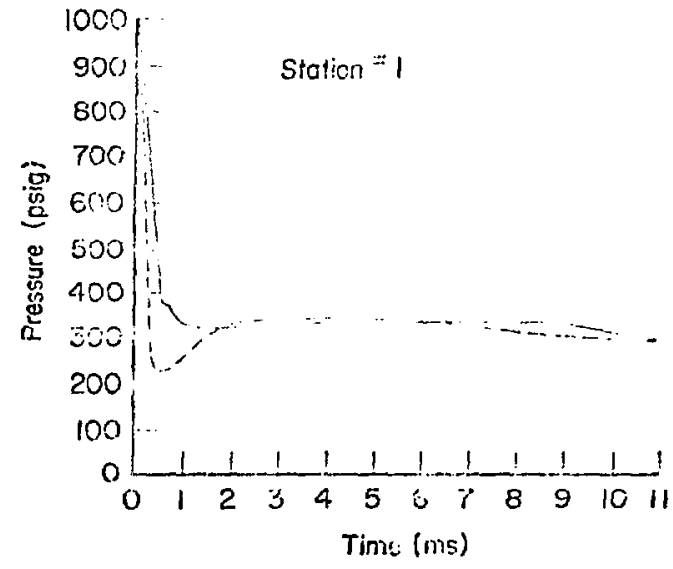

Fig. 1a. A comparison of standard difift-flux caliculation (dashed line) with experimental data (sol id line). Early time pressure history at gauge station 1 .

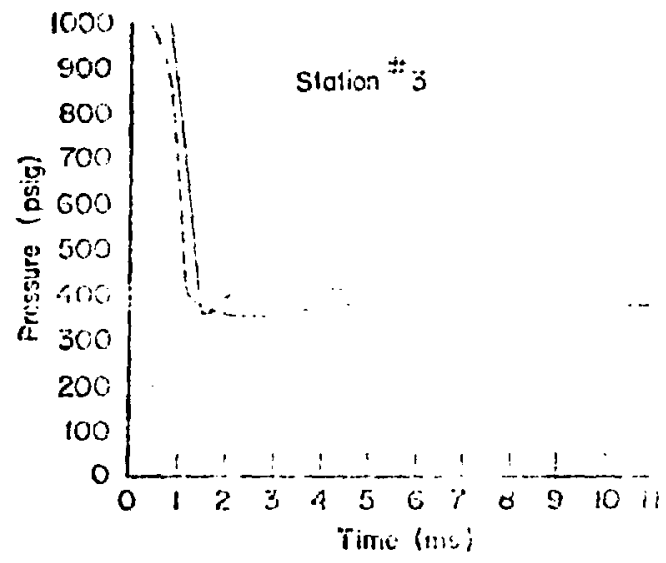

Fig. 1D. Early time pressure history at gauge station 5 .

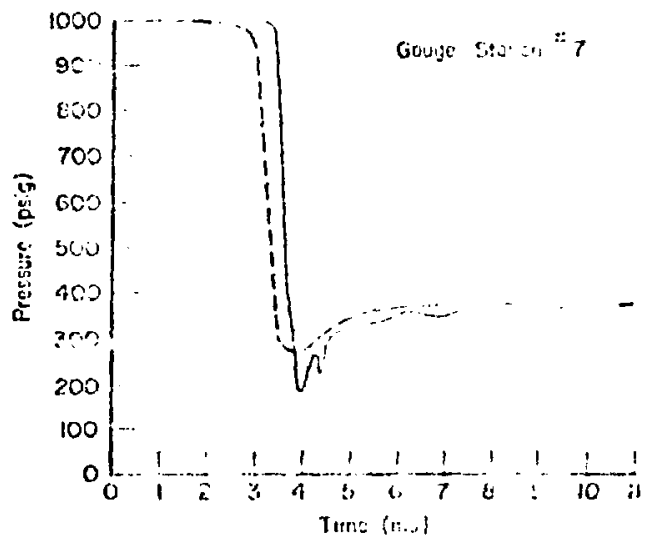

Fig. 1c. Early time pressure history at gauge station 7 .

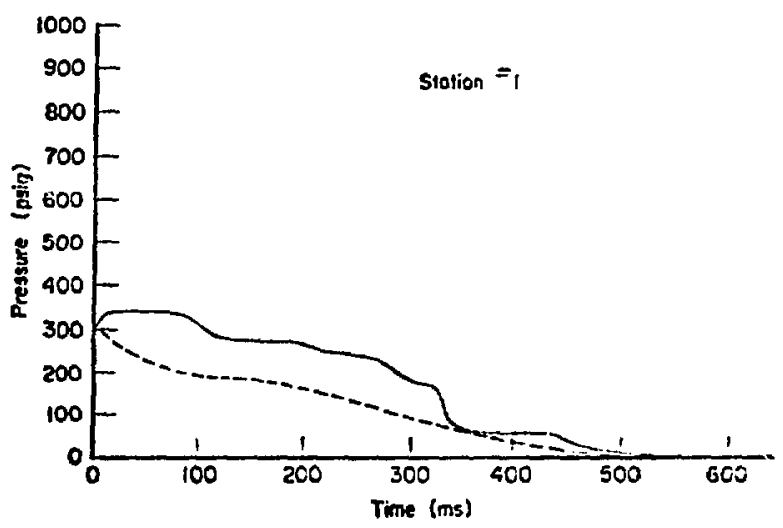

Fig. 1d. Complete pressure history at station 1. 


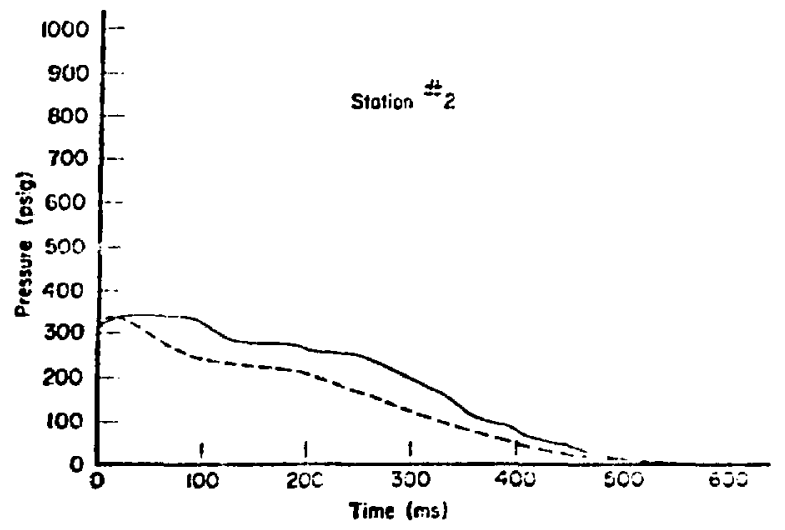

Fig. le. Complete pressure history at station 2.

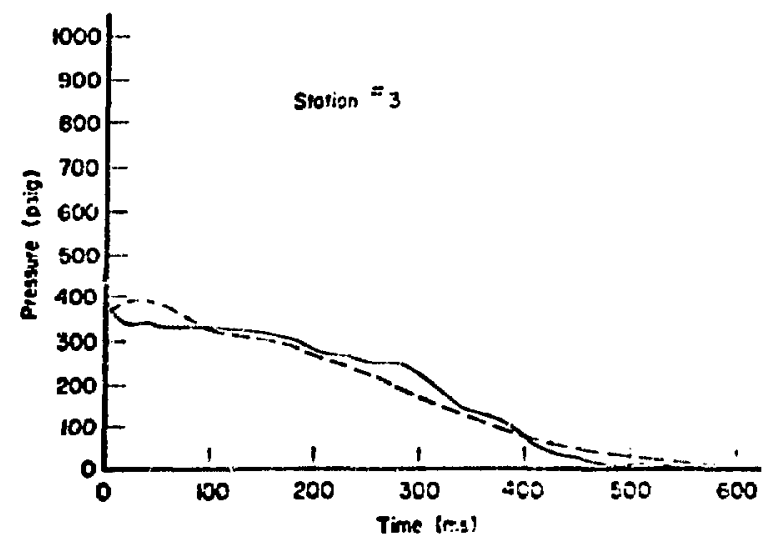

Fic. If. Complete pressure history at station 3.

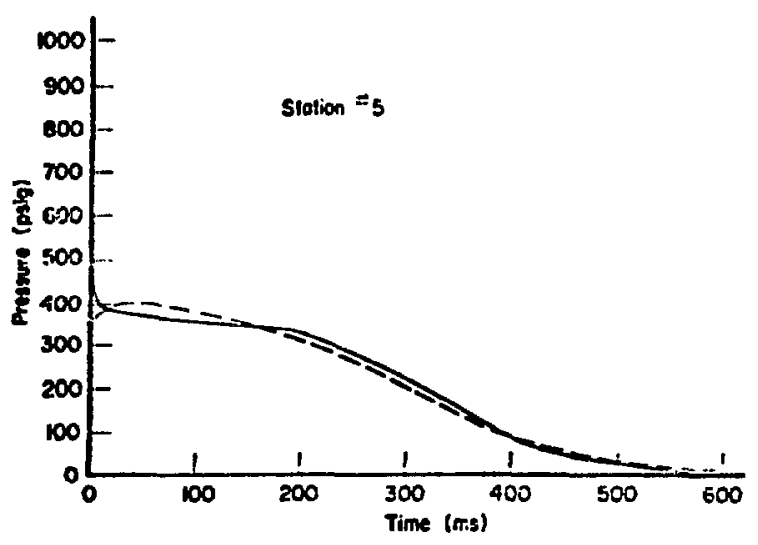

Fig. 1g. Complete pressure history at station 5 .

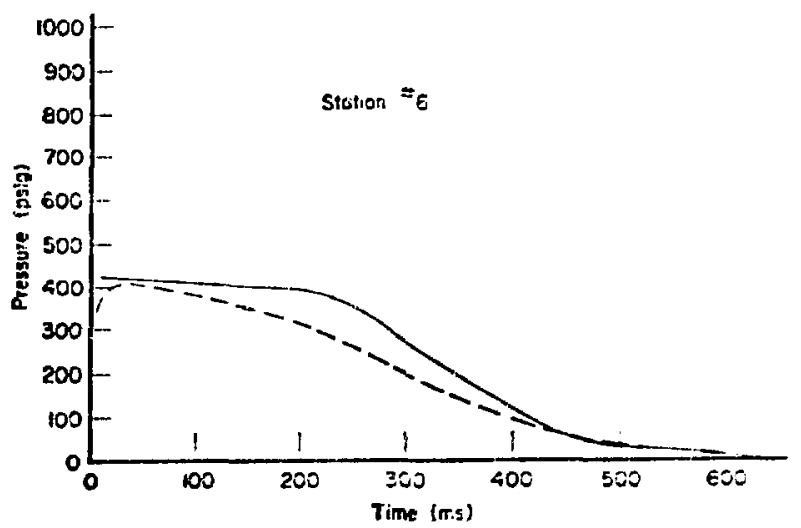

Fig. In. Complete pressure history at station 6.

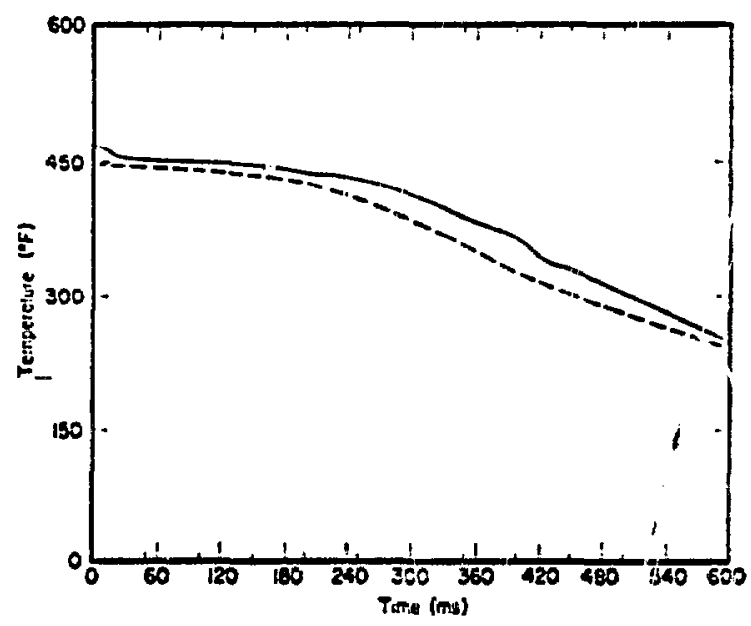

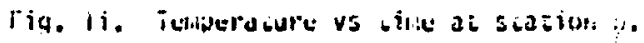

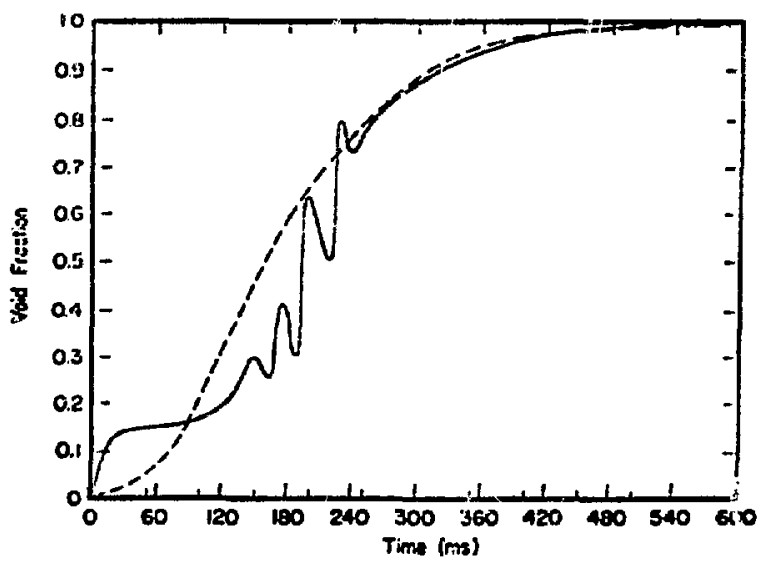

Fig. 1j. Void fraction vs time. 
inULE:

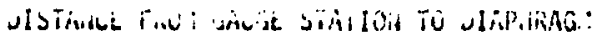

$$
\text { (j-ill. pipe) }
$$

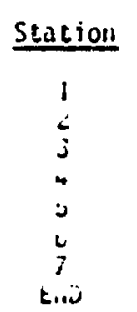

$$
\begin{gathered}
\text { sistance } \\
\text { (50) } \\
\hline \text { ie.u } \\
36.0 \\
116.1 \\
26 \% .3 \\
202.7 \\
313.2 \\
401.7 \\
6 i 3.0
\end{gathered}
$$

for three different rates are shown in Fig. 2 . The fastest rate, ${ }^{\prime}=620$, corresponds closely to an equilibriuli calculation. From this corparison, the rate $:=0.1$ w.:5 chosen as optimunil and was used in all other calculations.

It is worth noting that when the phase transition rate is set to zero after the initial depres. surization, say after $5 \mathrm{mis}$, the pressure at the closed end of the pipe is reduced from its saturated value of approximately 27 bars to 3 bars in 30 ms. This rapid bloudown is consistent with the expected transit time of a rarefaction wave in the frozen two-phase mixture,

$$
c=l_{i}^{i} \underline{v} c^{2}
$$

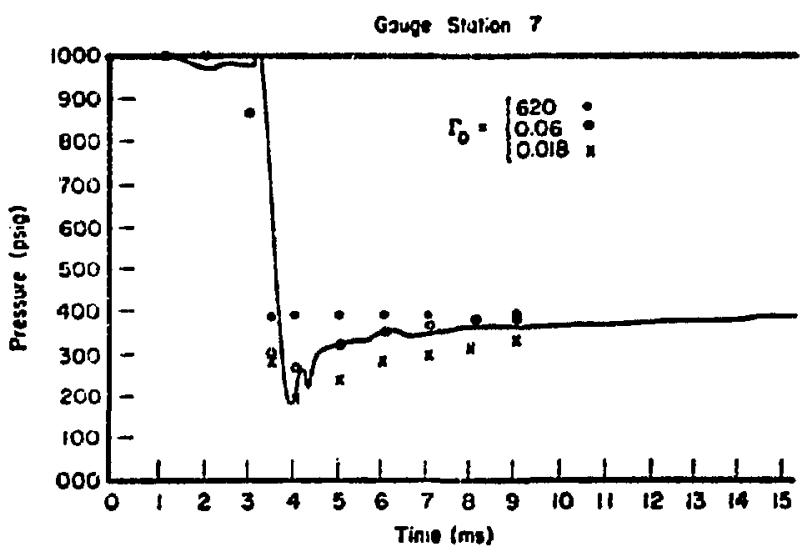

Fig. 2. Comparison of pressure histories at station 7 using three phase transition rates, $\Gamma_{0}$ equal to $620,0.06$, and 0.018 . Sol id line is experimental result. where $C$ is the artiabatic speed of sound in the vapor, the void fraction, " the microscopic vapor density, and the mean density. In the present case $C=15.6$ colms yielding a wave transit time down the pipe of 25 ms.

In the present application, the characteristic relaxation time for phase transitions to establish saturation, is less than 0.06\%: Therefore. processes occurring an tilite scales larger than 10 his are insensitive to the precise value of. when it exceeds 0.006 . In other words, values of :

in excess of 0.006 "ialy $h_{2}$ ve some influence on results during the initial depressurization, but little influence on the long time blowdown behavior.

The region of jreatest sisagreartent seincen tut siandard calculation and the data occurs at gauge station 1. that is, at the open end of the pipe. The calculated pressures dre consistently lower than those measured. Two possible explanations of this resuit have been investigated.

a. Because the nost rapid spatial variations in flow quantities are expected in the vicinity of gauge station 1, it is possible that vetter numerical resolution is required there. A partial tes: of resolution effects has been carried out by repeating the standard calculation, which used 40 zones in the pipe, witi 80 zones. A conparison of these results at station 1 is shown in Fig. 3 . ilo drastic changes are observed. This result reflects the fact that pressures. and other variables. do rot exhibit rapid spatial variations over the majority of the pipe length. Kowever. as we shall see, there is a sitall region of rapid charige right

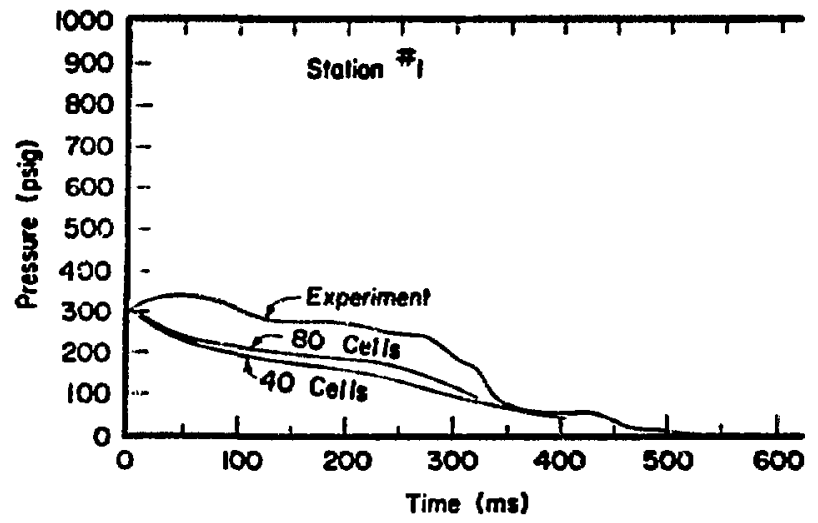

Fig. 3. Influence of 40- and 80-cell mesh resolution on pressure at gauge station 1 . 
at the exit plane. Nevertheless, in this region the pressure change is of the order of 2 bars and consequently a coarse approximation does not seriously affect the overall results. It appears, therefore, that numerical resclution is not the source of discrepancy with the experimental data at gauge station 1.

b. The exit region, at least until choking occurs, must be influenced by the choice of boundary conditions chosen to represent conditions outside the pipe. In the standard calculation the mesh is uly two cells wide outside the pipe and both phase transitions and relative velocities were set to zero in this region. To check this outflow boundary condition the standard calculation was repeated with a soncwhat larger liesh outside and the entire flow was computed in this region. That is, no special conditions bere specified at the end of the pipe. The exiting fiow was directly computed with the twodimansional. axisymetric capability of the SOLA-OF code.

Initially, because SOLA-DF is a one component code, the material outside the pipe was assumed to be vater vapor at a pressure of 1 bar and temperacure $3 B 6^{\circ} \mathrm{K}$. A comparison of pressure profiles obtained with the full calculation and with the standard calculation is shown in Fig. 4. The profiles are shawn at 300 nis after the diaphragm was broken. The small region of rapici pressure drop in the exit plane is clearly seen.

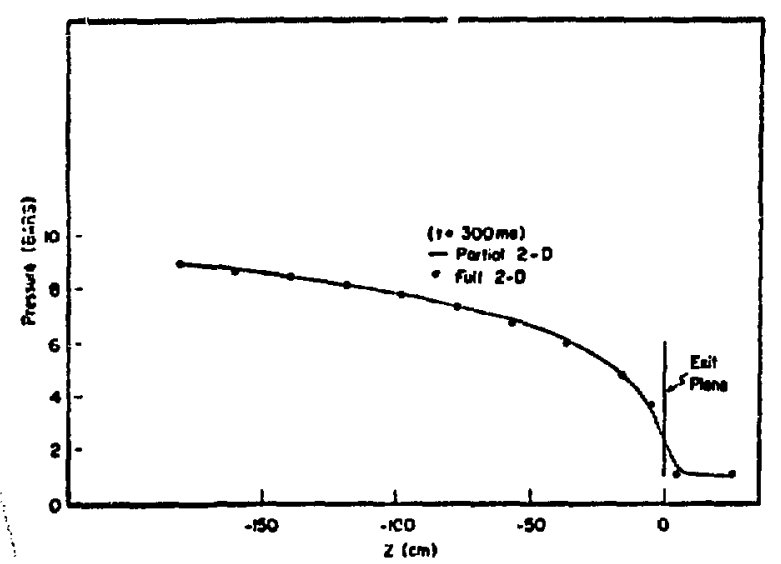

Fig. 4. Comparison of exit region pressure profiles at $t=300 \mathrm{~ms}$ using two different treatments for flow outside the pipe.
We conclude, therefore, that the choice of boundary condition at the pipe exit does not affect the flow. How, then, can we explain the observed disagreement? When all else fails one is tempted to blame the experimental data. Some support for this conclusion, is, in fact, available.

We have used the same calculational model to co:npute the blowtown of an $\mathrm{z}-\mathrm{in}$. pipe. In this experiinent the water was initially at a pressure of 58 bars and was reported to be at a temperature of $515 \%$. As in the 3-in. pipe test, novever, we used an initial temperature of $502.2^{\circ} \mathrm{K}$. Results of this calculation are compared with the experinental data of Ref. 4 in Figs. 5a-f. In this case, the pressure history at gauge station $l$ is seen to be in quite good agreement.

In addition to the calculations described above, various other parameter and constitutive model variations were tried to ascertain the sensitivity

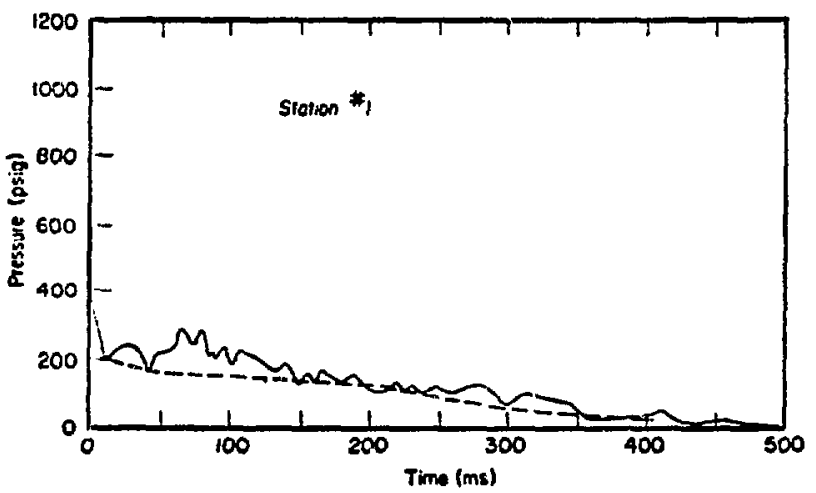

Fig. 5a. Comparison of calculated results (dash lines) with experimental data (solid lines) for b-in, pipe. Pressure history is sinovin for station 1 .

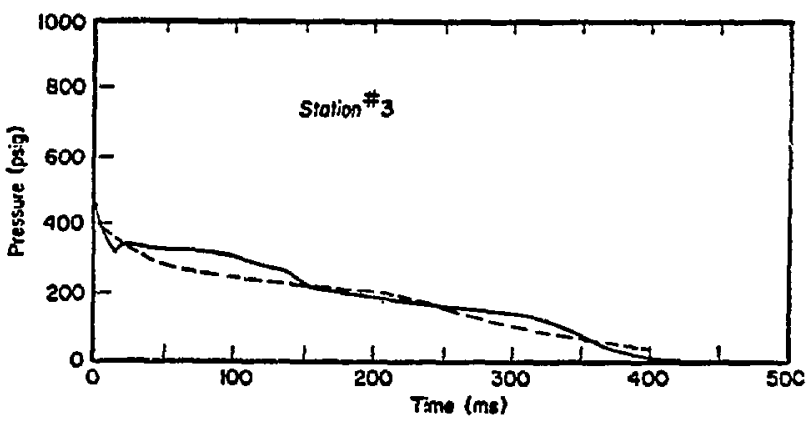

Fig. 5b. Pressure history at station 3 for 8-in. pipe. 


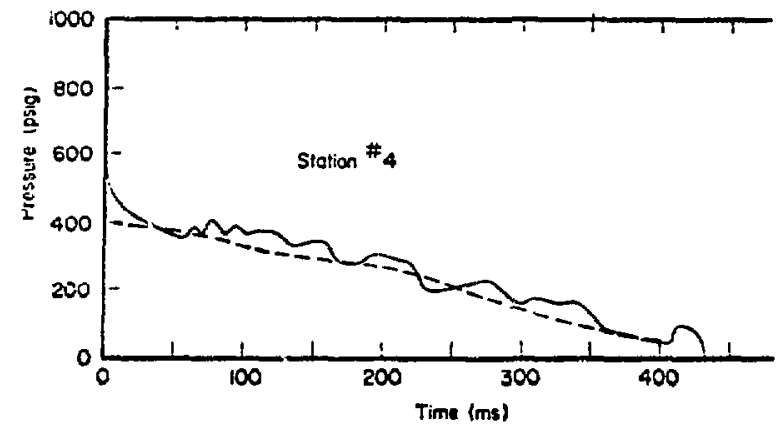

Fin. Sc. Pressure nistory at station 4 for $z=i n$. pipe.

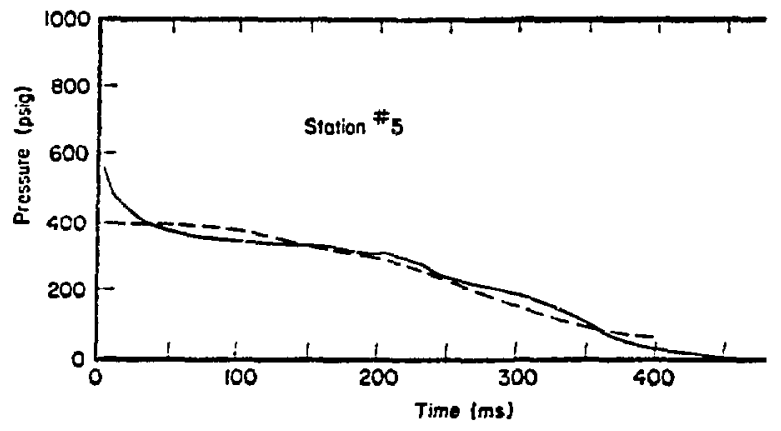

Fig. bd. Pressure history at station $b$ for o-in. pipe.

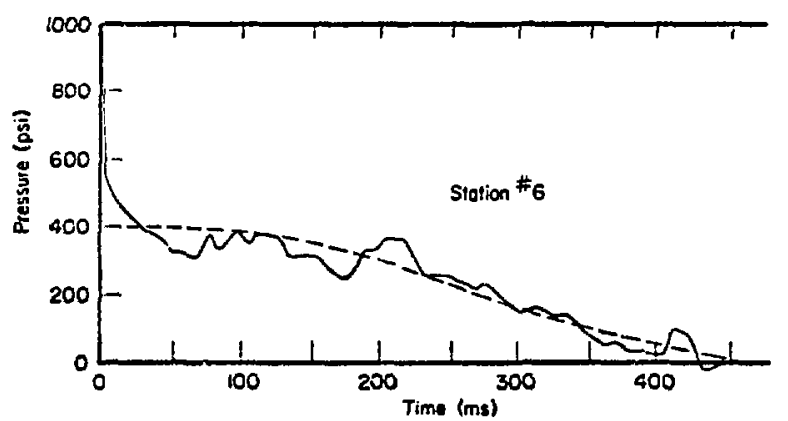

Fig. se. Pressure history at station $\delta$ for 8 -in. pipe.

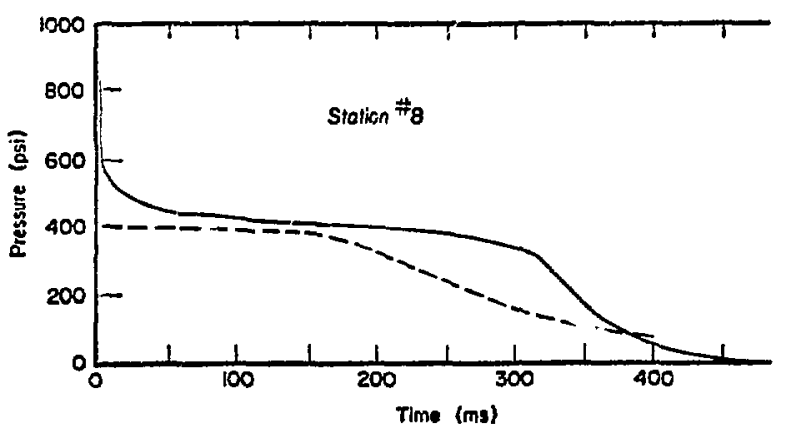

Fir. 5f. Pressure history at station 8 for 8-in. pipe. of the computed result to these changes. The must sensitive feature of the mode? is the choice of a suitable pipe friction. Two basic variations in this friction were investigated. First, to obtain reasonable agreement with the data, a rough ratner than smooth pipe must be assumed. Without roughness the friction tenas to small values at hign Reynolds numbers and the pressures in the pipe approach ambient values too quickly. The rougnness chosen for the standard calculation is typical of sonething between drawn steel and structural steel, but it should be noted that variations in roughness about this value, by factors of $4, \cdots: 0$, do not produce major changes in the computed results (less than ? bar in corresponding pressure histaries.) It. should also be noted that the experimenters reported rust deposits in their pipr, so the assumption of a rough pipe is justified.

The second friction variation considered was the choice of a suitable two-phase friction multiplier.' Two forms were tried, as described in Section IIB. These forms correspond to extremes that have been related to annular and homogeneous flow regicies. A comparison of results cbtained with these two choices for a friction multiplier is shown in fig. 6. The annular type flow model is seen to give the best agreement with data. Results. obtained from a more complicated friction multiplier recommended by Chisnoim are also shown for comparison. The Chisholm forn approximates the homogeneous flow model and, therefore, does not give the best

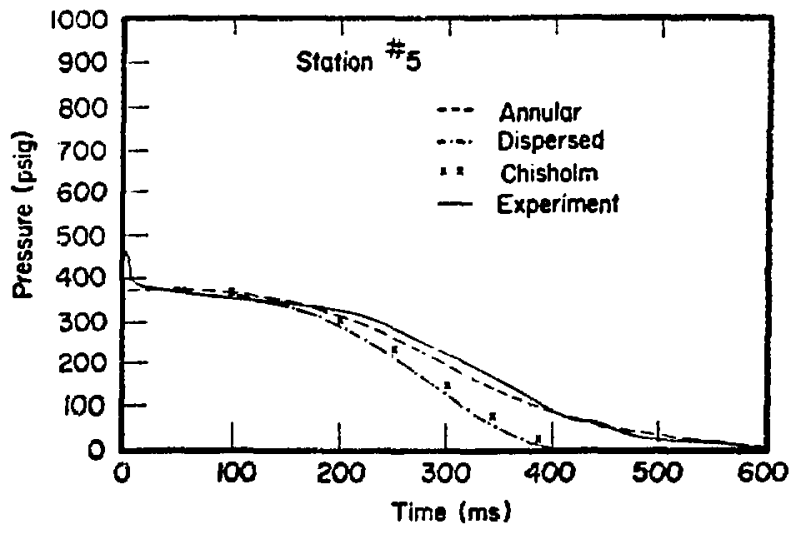

Fig. 6. Comparisor of calculated pressure histories at station 5 using three different twophase friction multipliers. 
results. Aithourgh the annular type multiplier was best this does not mean the fluw was actually in an ansular configuration, which is unlikely in the pipe blcosdo:ns. 13. is simply a particular choice of void derenfencs for : ip.

\section{iY. COLCLUDIHG COHAENTS}

As an illustration and test of the SOLA-Uf code a detailed study was undertiken of the transiant blowdrwn of long straight pipes filled with subcooled watar. Good agreenent bas obtained with experimentally measured pressure histories at nearIy all tae gauge stations. A sensitivity study was a) so performed to detemine whicin paraneters or constitutive models most influence the computational results. Pipe friction emerged as the mos: sensilive feacure. An annuler flow modei for the two-phase friction rituliplier. together with the assumption of a rough pipe, gave the best agreement with data.

1: appears to us trat the hajor remaining disagreement between theory and experiment is in the choice of the initial water temperature. Botin the 3-in. and u-in. pipe txperiments vere reported to start witn an initial temperature of $20 \% \%$. If one assunes that tine water boils after the intial depressurization and reaches a saturation pressure correspondinc $c_{j}$ to $: 15^{\circ} \%$. this pressure would be arproximately 6.8 bars (100 psi) above that observed. It is because of this that previcus caiculations have started with a lomer initial tentperature (approximately $502.2^{\mathrm{K}} \mathrm{K}$ ). Because it seems untikely that initial temperature neasurements in two different experimental arrangements would be equally in error by $13^{\circ} \mathrm{K}$. some resolution of this discrepancy bust be sought. This is particularly essential if we are to have a truly predictive theory.

One possible explanation that we have investigated is due to Edwards ${ }^{4}$ who argues that the boiling precess should be controlled by heat conduction. That is, after the initial depressurization wave passes through the water it begins to boil (vaid fraction measurements indicate no significant delay in boiling) and it is easy to inagine that liquid in the vicinity of a vapor bubble is somewhat cooler than the bulk of the liquid because of the loss of latent heat required for boiling. Therefore, boiling will locally cease when the vapor is at saturation with this lower adjacent liauid temperature. Given slifficient time, of course, molecular heat conduction in the liquid will raise the liquid telliperature at the bubble interfact and the vapor pressure will eventuatiy come into equilibrium with the hi her bulk liauid remperature. The entire pipe biowdown process, however, takes place in rouginly 0.55 so that no iecular heat conduction has little time to operate, In the other hand, when the fluid begins to flow down the pipe a considerable amount of turbulence is produced that mixes the two-phase material and one than expects aduitional vaporization to accur. In tems of the above picture, after the initial depressuri. zation, vapor is produced and reaches saturation at a iocal tenperatiore $T_{\text {SAT }}$ somewhat below the bulk linuid temperature (Say $T_{S A T}=502 \mathrm{~K}$ instead of $515 \mathrm{k}$. Then as turbulence is generated TSAT relaxes to the bulk liquid temperature. To test this idea we somewhat aroitrarity defined the saturation temperature used in the phase transition model to be

$$
i_{S A T}=T\left(1.0-\frac{0.025 R}{R_{C}+R_{e}}\right)
$$

where $R_{e}$ is the local Reynoids rumber and $R_{-}=10^{7}$ is a reference value. Initially, when $T=515^{\circ} \mathrm{K}$ and the flow is nearly at rest, we have $R_{e}<R$, and $T_{\text {SAT }}=502^{\circ} \mathrm{K}$.

Using the above definition of $T_{\text {Sat }}$ the standard calculution of the 3-in, pipe blowdown was repeated. Selected results frnm this calculation are compared with experimental data in Figs. 7a,b. The comparisons are good and in the case of gauge station 6 much better than those obtained in the standar:: calculation, which used an initial temperature of $502.2^{\circ} \mathrm{K}$. Previous calcuiations could not reproduce the high pressures observed at the closed end of the pipe, since the pressure at each station more or less uniformly decreases as the expansion wave passes up the pipe. The modified TSAT expression allows a higher saturation temperature as flow commences, wilich acts as a source of additional pressure to compensate for the expansion wave.

Further support for this explanation of the apparently low saturation pressure can be obtained from a careful examination of the experimentally 


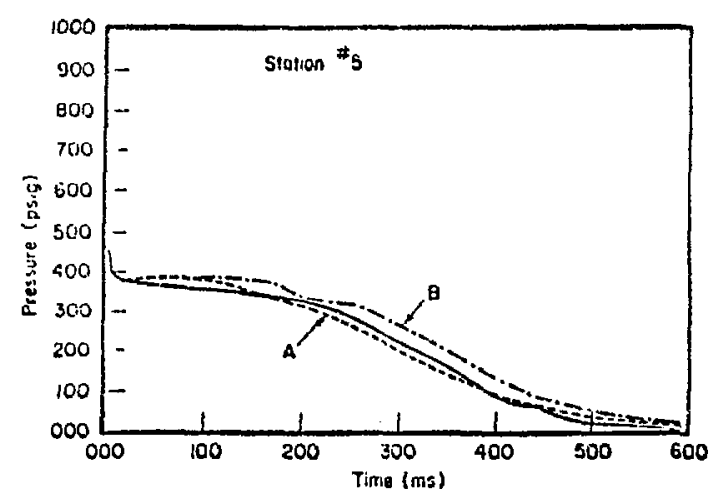

Fig. 7a. Comparison of pressure histories at ita tion 5 , (A) using initial $502^{\circ} \mathrm{K}$ temperature ard $(B)$ using initial $515^{\circ} \mathrm{K}$ temperature, witi data (solid line).

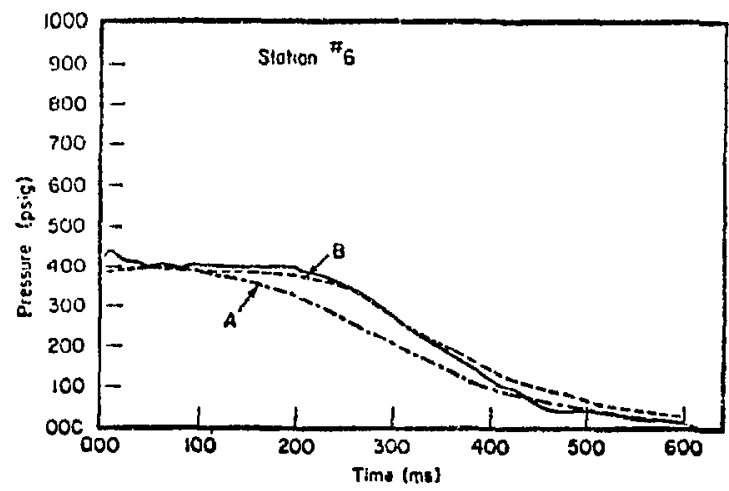

Fig. 7b. Comparison of pressure histories at station 6 obtained using (A) $502^{\circ} \mathrm{K}$ initial temperature and $(B) 515^{\circ} \mathrm{K}$ initial temperature with data (solid line).

recorded temperature at gange station 5, rig. $1 i$. The temperature is at the reported $515^{\circ} \mathrm{K}$ initial value at the beginning of biowdown, but takes a sharp plunge to approximately $502^{\circ} \mathrm{K}$ after about 30 ms. This same behavior is observed in the $\delta$-in, pipe experiments as well. Detailed void fraction measurements in the 8 -in. pipe have indicated that most of the vapor is located at the walls, forming a vapor annulus at early times. Because the thermocouples extend into the pipe bore approximately $1 / 2$ in., we would expect them to measure the bulk temperature of the liquid $\left(575^{\circ} \mathrm{K}\right)$ until the vapor annulus has grown large enough to cover them, at which time they should record the vapor temperature. The void fraction necessary for an annulus of $1 / 2-i n$. thickness in the 8 inch pipe is roughly $\theta=1 / 4$. A measured average void. value of $1 / 4$ was attained at $60 \mathrm{~ms}$ in the 8 -in. pipe experinent, which is not far from the observed 30-ils time.

Although the model proposed above is very crude, it does indicate that physical arguments are available to reconcile the apparent disagreement in initial temperatures. If further testing indicates that such a modei is well founded then it shouid be possible to construct $T_{S A T}$ from first principles to provide a true predictive capability.

For completeness we have included Figs. 8a-g, which show the profiles of $\rho, E, P, p_{v}$. Mach number, $\theta$, and relative axial velocity vs mean axial velocity as functions of the axial distance, $z$, along the pipe, at 300 ms for the standard calculation described in Section III.

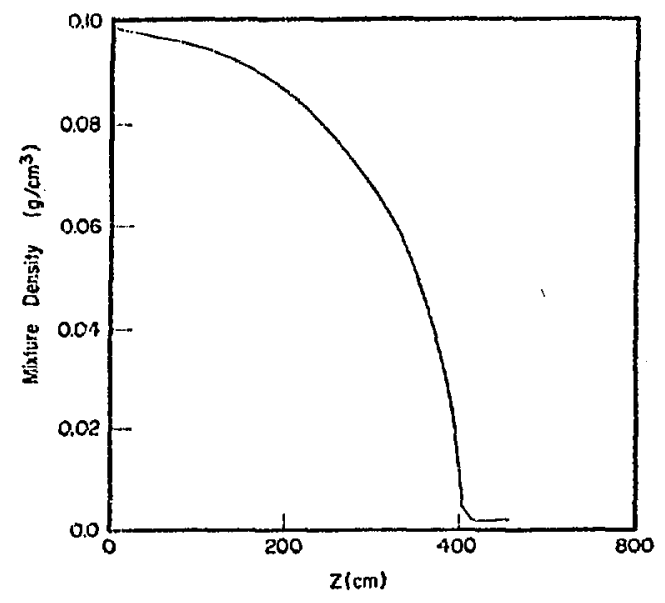

Fig. 8a. Axial profile of $\rho$ at $300 \mathrm{~ms}$.

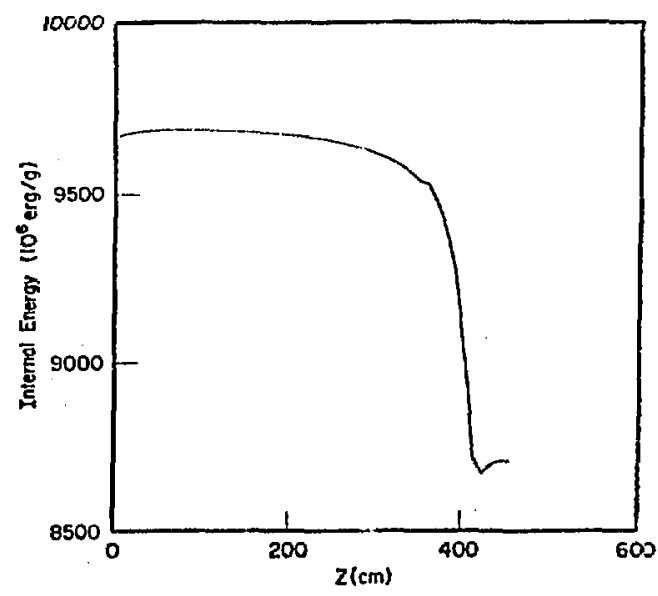

Fig. 8b. Axial profile of I at $300 \mathrm{~ms}$. 


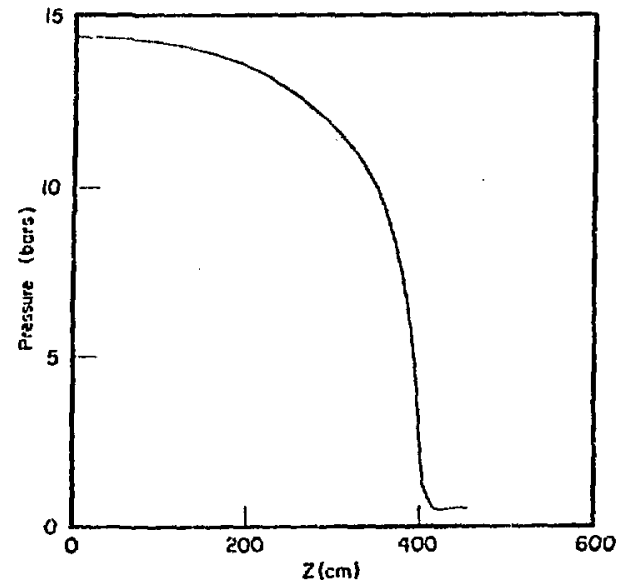

Fig. 8c. Axial profile of $p$ at 300 ils.

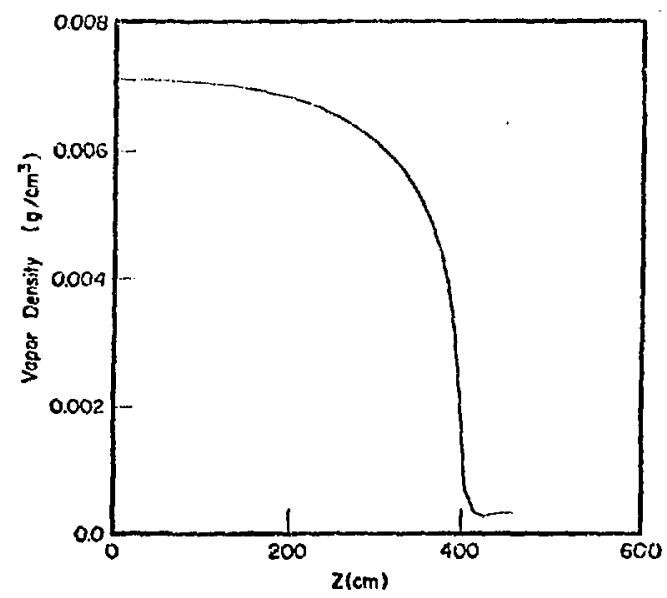

Fig. 8d. Axial profite of $\rho_{v}$ at $300 \mathrm{~ms}$.

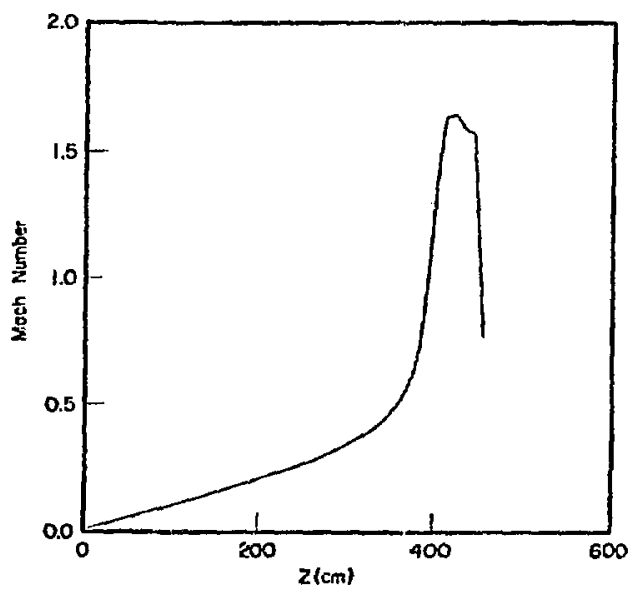

Fig. 8e. Axial profile of Mach number at $300 \mathrm{~ms}$.

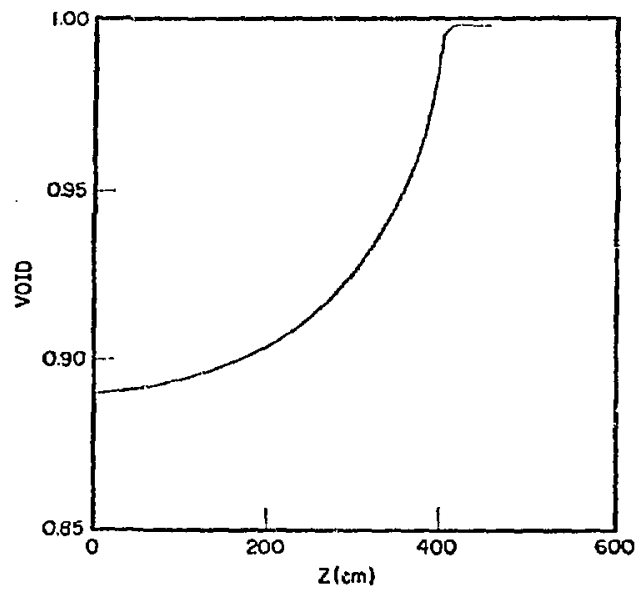

Fig. 8f. Axial profile of $\theta$ at $t=30 \mathrm{~ms}$.

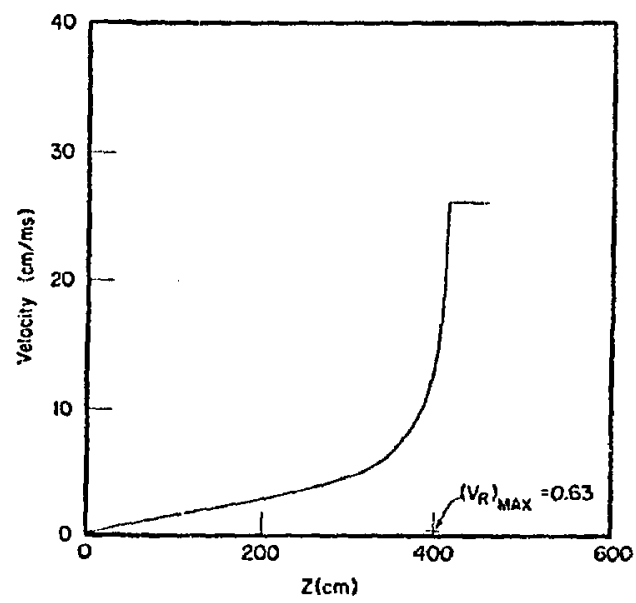

Fig. dg. Axial profiles of relative velocity vs mean velocity at $300 \mathrm{~ms}$.

The standard pipe blowdown problem described in this report is also under investigatio:1 with two other computer codes. One of these, SOLA-PLOOP, is a primitive 10op code for systems studies that uses as a basis a one-dimensional version of the SOLA-DF code. This code is being used for a nore complete modeling study. In particular, we are investigating the loss of accuracy as the number of celis used to represent the pipe is decreased. The second code, KACHINA, ${ }^{6}$ is based on a complete two-fluid model. When operated under the equal phase temperature condition imposed in the SOLA-DF code it gives nearly identical results. However, it has also been used 
to investigate the influence of unequal phase temperatures. Some preliminary results obtained with KACHIIA are descrited in Ref. 7. Both tile SOLA-UF and KACHIiA programs are currently being used to study in more detail a variety of one- and twodimensional choked flows. These studies are part of a broad research promran sponsured by IIRC-RSSR to develop better theoretical tools for tre prediction of two-phase fluid flows.

\section{ACKNONLEDGMENTS}

This work has greatly benefited from the advice of our colleagues, especially $W$. Rivard and T. D. Butler. We also thank Louis Shotkin for several helpful suqnestions and for his critical conments.

APPENDIX

FORMULATION OF DRIFT-FLUX MODEL FOR THE SOLA-DF COMPUTER CODE

The SOLA-DF code is a finite difference solution technique for the drift flux equations ${ }^{3}$ describing two-phase fluid dynamics. The drift model equations considered here are for transient flows in two-dimensional plane $(x, y)$ or axisymmetric $(r, z)$ coordinates.

The basic dependent variables are:

$\rho_{v}$, the macroscopic vapor density

$\rho$, the average vapor-liquid density

$U, V$, the $(x, y)$ or $(r, z)$ mass averaged velocity components (i.e., center of mass velocities)

I, the average specific internal energy. nther variables used in the following description, and their relationship to those above, are:

$P$, pressure

Q, the void fraction $\left[\rho_{v}=\theta \rho_{v}^{0}\right.$, where $\rho_{v}^{0}$ is the microscopic vapor density]

$\rho_{\ell}$, the macroscopic liquid density $\left[\rho=\rho_{v}+\right.$ $\rho_{\ell}$ and $\rho_{\ell}=(1-\theta) \rho_{\ell}^{\circ}$, where $\rho_{\ell}^{\circ}$ is the microscopic liquid density]

$T$, temperature

$N$, number of bubbles (or drops) per unit volume

$r_{b}$, an average vapor bubble (or liquid drop) radius $\left[r_{b}=\left(\frac{3 \theta}{4 \pi N}\right)^{1 / 3}\right]$

$U_{r}, V_{r}$, relative velocity components, defined as $u_{r} \equiv U_{v}-U_{l}$ and $v_{r}-v_{l}$. [in terms of $\vec{b}$ and $\vec{v}_{r}$ the component velocities are $\vec{U}_{V}=\vec{U}+\frac{P_{\ell}}{\rho} \vec{U}_{r}$ and $\left.\vec{U}_{\ell}=\vec{U}-\frac{P_{v}}{\rho} \tilde{U}_{r} \cdot\right]$

$\Gamma$, rate of vapor mass production per unit volume by phase transitions

$K$, interfacial friction coefficient (defined in section on constitutive relations).

$f_{V I S}$, viscous stresses, including pipe friction

WIS, viscous heating

$Q$, heat conduction sources

$g_{x}, g_{y}$, body acceleration (usually gravity)

$\lambda$, latent heat of vaporization.

In terms of the chosen dependent variable set, the tasic drift-flux equations are

$$
\begin{aligned}
& \frac{\partial \rho}{\partial t}+\nabla \cdot \rho \vec{U}=0 \\
& \frac{\partial \rho_{v}}{\partial t}+\nabla \cdot\left(\rho_{v} \vec{U}+\frac{\rho \rho_{\ell}}{\rho} \vec{U}_{r}\right)=\Gamma
\end{aligned}
$$




$$
\begin{aligned}
& \frac{\partial \rho \hat{U}}{\partial t}+\nabla \cdot\left(\sigma \vec{U} \vec{u}+\frac{\rho^{\rho} \varepsilon}{\rho} \vec{u}_{r} \vec{u}_{r}\right)= \\
& -\nabla p+\rho \vec{g}+f_{V I S} \\
& \frac{\partial \rho I}{\partial t}+\nabla \cdot\left[\rho I \vec{U}+\frac{\rho_{v} \rho_{l}}{\rho}\left(I_{v}-I_{\ell}\right) \vec{u}_{r}\right]= \\
& -P \nabla \cdot\left[\vec{U}+\frac{\rho_{v} \rho_{l}}{\rho}\left(\frac{1}{\rho_{v}^{o}}-\frac{1}{\rho_{l}^{o}}\right) \vec{u}_{r}\right] \\
& +k \vec{u}_{r} \cdot \vec{u}_{r}+w_{V I S}+Q
\end{aligned}
$$

The divergence operator in these equations has conponents $\left(\frac{\partial}{\partial x}, \frac{\partial}{\partial y}\right)$ in plane coordinates and $\left(\frac{1}{r} \frac{\partial}{\partial r} r\right.$, $\frac{\partial}{\partial z}$ ) in cylindrical coordinates.

To complete these equations a variety of constitutive relations are required. Those currently employed for pipe blowdown calculitions are:

\section{The Void Fraction}

The void fraction, $\theta$, must be specified to relate the microscopic and macroscopic densities. For this purpose we assume that the microscopic liquid density, $\rho_{\ell}^{0}$, is constant so that

$$
(1-0) 0_{\ell}^{0}=\rho-p_{V}
$$

or

$$
\theta=\left(\rho_{\ell}^{0}-\rho+\rho_{v}\right) / \rho_{\ell}^{0} .
$$

The microscopic liquid density couid also be a specified function of temperature or pressure.

\section{E. Equation of State}

The pressure, $P$, of the two-phase mixture must be given by a suitable equation of state. The assumption that the liquid phase is incompressible is a good approximation when the speed of sound in the liquid is much greater than that in the vapor. In this limit the liquid phase pressure will be in equilibrium with the vapor phase pressure. Thus, in a two-phase mixture the pressure is obtained from a vapor equation of state, for which we use the polytropic gas equation

$$
P=(\gamma-1) \rho_{v}^{\circ} I_{v}
$$

In the pressure and temperature range of interest $\gamma=1.07$ is a good approximation for the specific heat ratio. This equation can only be used when there exists some vapor, say $\theta \geqslant \theta_{c}$ where $\theta_{c}$ is some small value.

In the initial depressurization of pipes, when the pressure exceeds the vapor pressure of the liqui and $\theta \leqslant{ }^{g}{ }_{c}$, we must also have a pure liquid equation of state. For this purpose a simple stiffened gas equation is used

$$
P=P_{0}+a^{2}\left(p-0_{l}^{0}\right)
$$

where $a^{2}$ is the square of the speed of sound in pure liquid. The value of $P_{D}$ is chosen to insure pressure continuity between the two equations of state when $\theta=\theta_{c}$, i.e.,

$$
P_{0}+a^{2}\left(\rho-0_{l}^{0}\right)=(\gamma-1) \frac{\rho_{v}}{a_{c}} I_{v}
$$

when

$$
\rho=\left(1-\theta_{c}\right) \rho_{\ell}^{\circ}+\rho_{v}
$$

Thus,

$$
P=a^{2} \rho_{\ell}^{0}\left(\theta_{c}-\theta\right)+(\gamma-1) \frac{\rho_{v}}{\theta_{c}} I_{v}
$$

is used for the equation of state when $e \leqslant \theta_{c}$.

Currently in SOLA-DF, $a_{c}=0.005$ and $a=123.4$ $\mathrm{cm} / \mathrm{ms}$.

3. Internal Energy and Temperature

The equation of state and the drift convection of internal energy require a knowledge of $I_{v}$ and $I_{l}$. Currently, these quantities are computed in the SOLA-DF code under the assumption that the liquid and gas phases are at the same temperature. To this end we must define $I_{V}$ and $I_{Q}$ as functions of the temperature, $T$. In the range of temperatures under investigation the following linear approximations are used,

$$
\begin{aligned}
& I_{v}=E_{v}+C_{v}\left(T-T_{0}\right) \\
& I_{\ell}=E_{\ell}+C_{\ell}\left(T-T_{0}\right)
\end{aligned}
$$

where $E_{v}$ and $E_{\ell}$ are constants equal to the saturated internal energies of vapor and liquid, respectively. 
at the temperature $T_{0}$. The specific heats, $C_{V}$ and $C_{k}$, are chosen to give the best fit to the saturated values of $I_{v}$ and $I_{Q}$ in the interval $300.0<T<525.0$. values of the constants in units of $\left(\mathrm{gm}, \mathrm{cm}, \mathrm{ms},{ }^{\circ} \mathrm{K}\right.$ ) are

$E_{v}=2.506 \times 10^{4} \quad E_{l}=0.4174 \times 10^{4} \quad T_{0}=373$.

$C_{V}=6.67 \quad c_{\ell}=44.34$

With the above definitions, and the assumption of equal vapor and liquid temperatures, the temperature can be easily computed from the mixture internal energy

$$
\begin{aligned}
\rho_{I} & =\rho_{v} I_{v}+\rho_{\ell} I_{\ell}=\rho_{v}\left[E_{v}+C_{v}\left(T-T_{0}\right)\right] \\
& +\rho_{\ell}\left[E_{\ell}+C_{\ell}\left(T-T_{0}\right)\right]
\end{aligned}
$$

or

$$
T=T_{0}+\frac{\rho !-\left(\rho_{v} E_{v}+\rho_{\ell} E_{\ell}\right)}{\rho_{v} C_{v}+\rho_{\ell} C_{\ell}} .
$$

This temperature may then be used to compute values of $I_{V}$ and $I_{\ell}$. The assumption of equal temperatures in the two phases may be criticized when heat conduction between phases is sma11. Thus, it is reasonable to ask for alternatives. One alternative that has been suggested is to assume the vapor phase be at saturation with the local pressure. If the liquid is treated as incompressible, as proposed here, the void fraction can still be determined as in Sec. 1 from $\rho$ and $\rho_{v}$, and the two-phase pressure is equal to the pressure of the vapor which is a function of $\rho_{v}^{0}$ only. In keeping with our previous ideas, we define

$$
I_{v}^{S A T}=E_{v}+C_{v}\left(T_{S A T}-T_{0}\right)
$$

where the vapor saturation temperature $T_{S A T}$ is determined from $P$. A good approximation is

$$
T_{\text {SAT }_{V}}=255.2+117.8 \mathrm{p}^{0.223}
$$

Then the equation

$$
P=(\gamma-1) \rho_{v}^{\circ} I_{v}^{S A T}
$$

relates $P$ and $\rho_{v}^{\circ}$.

Given that $I_{V}=I_{V}^{S A T}$ we can unfold $I_{\ell}$,

$$
I_{\ell}=\frac{\rho I-\rho_{v} I_{v}}{\rho_{\ell}}
$$

From $I_{\ell}$ and $I_{V}$ separate temperatures can be computed for each phase.

The assumption that $\rho_{v}^{0}$ is at saturation with respect to $P$ would also seem to imply an arbitrarily fast rate of condensation and heat conduction between phases to the extent of keeping $T_{v}$ equal to $T_{\text {SAT }}$. The choice between this alternative, equal phase temperatures, or some other scheme, will have to wait until more experience has been gained in applying them to real problems. For the pipe blowdown calculations the equal phase temperature assumption has been used.

\section{4. interfacial Friction}

In SOLA-DF the relative siip velocity is computed from a balance of interfacial friction and pressure gradient forces. This requires, therefore, a definition of the interfacial friction. We define the friction force per unit volume exerted on the liquid by the vapor as

$$
K\left(\vec{U}_{v}-\vec{U}_{\ell}\right)=k \vec{U}_{r} .
$$

When there is little vapor ( $\theta$ small) we approximate the friction by the drag of a single bubble times the number of bubbles per unit volume, i.e.,

$$
K=\frac{3}{8} \rho_{\ell}^{0}\left[C_{d}\left|\vec{U}_{r}\right|+\frac{12 \nu_{l}}{r_{b}}\right] \frac{\theta}{r_{b}} \text { for } \theta \text { small }
$$

When there is a lot of vapor ( $\theta$ large) we expect the friction to be approximated by the drag on a liquid drop times the number of drops per unit volume,

$$
K=\frac{3}{8} \rho_{v}^{\circ}\left[c_{d}\left|\vec{u}_{r}\right|+\frac{12 v_{g}}{r_{d}}\right] \frac{(1-\theta)}{r_{d}} \text { for } \theta \text { large }
$$


wisere the drag coefficient $C_{d}$ is 0.5 for spherical drops. Assuming $N$ drops or bubbles per unit volume, their average radius is

$$
r_{b}=\left(\frac{3 \theta}{4 \pi N}\right)^{1 / 3}
$$

for bubbles $(t<1 / 2)$

or

$$
r_{d}=\left[\frac{3(1-\theta)}{4 \pi N}\right]^{1 / 3} \quad \text { for drops }(\theta>1 / 2) .
$$

A smooth transition between the two limiting cases of bubbles and drops is provided by

$$
K=\frac{3}{8} \rho\left[C_{d}\left|\vec{u}_{r}\right|+\frac{12 v}{r_{0}}\right] A \text {, }
$$

Where $\rho=\theta \rho_{v}^{0}+(1-\theta) \rho_{\ell}^{0}, v=\theta v_{g}+(1-\theta) v_{\ell}$ and where $A=\frac{\theta}{r_{b}}$, and $r_{0}=r_{b}$ if $\theta \leqslant 1 / 2$ or where $A=\frac{1-\theta}{r_{d}}$, and $r_{0}=r_{d}$ if $\theta>1 / 2$.

The above prescription for $K$ requires the knowledge of $N$, the number of bubbles per unit volume. In the present version of SOLA-DF we input this as a fixed constant, which for the pipe blowdown calculations is typically $10 / \mathrm{cm}^{3}$. This number is not crucial, however, and has been varied from 1 to 1000 with little effect observed in the results.

\section{Relative Velocity}

An equation of motion for the relative velocity can be derived from equations describing a complete two-fluid model . In the event of large interfacial friction, a quasi-equilibrium is established in which this friction force is balanced by the local pressure gradients. In this limit then, the relative velocity is given by

$$
K U_{r}=\frac{\theta(1-\theta)\left(\rho_{v}^{0}-\rho_{l}^{0}\right)}{\rho} \nabla P
$$

where $K$ is the function defined in Sec. 4. Eq. (A.9).

The relative velocity given by Eq. (A.10) is based on the velocity of individual bubbles or drops. No account of inter-bubble or inter-drop effects has been incorporated. It has been suggested, and experiments have yerified, that these effects can can be modeled by including an additional void fraction dependence in the definition of the relative velocity. A recommended approximation for this is to multiply the right side of Eq. (A.10) by $(1-a)^{2(n-1)}$ where $\alpha$ is the volune fraction of the dispersed phase (i.e., $\alpha=0$ for bubbles and $\alpha=1-i$ for drops). Typical values for $n$ are 1.5 for bubbles and 2 for drops. Since this factor tends to unity in the limiting cases of all or no yoid, we have generally omitted it when calculating the relative velocity.

For the present application we have inserted, instead, a factor of $\alpha$ to account for added mass effects, which are expected to be significant in the rapid transients encountered in the pipe blawdowns. This factor, which is equal to $\theta$ for $\theta \leqslant$ $1 / 2$ and $1-\theta$ for $\theta \geqslant 1 / 2$, suppresses the initial drift of bubbles in the pipe when $\theta$ is small and the drift of drops outside the pipe where $\theta$ is large. Comparisons of pipe blowdown calculations with and without this extra factor, however, show little difference.

\section{Phase Transitions}

Phase transitions have been incorporated into SOLA-DF in a very simple way. He assume that the vapor density is always attempting to relax to its saturated value with respect to the liquid tomperature, i.e.,

$$
\Gamma=\Gamma^{\star}\left(\rho_{\mathrm{SAT}}-\rho_{\mathbf{v}}\right)
$$

where $\Gamma^{*}$ must have dimensions of inverse time.

Simple arguments suggest that $\Gamma^{\star}$ must be proportional to the area of contact between the phases per unit volume and proportional to some microscopic characteristic velocity. We use

$$
\Gamma^{*}=\Gamma_{0} A I_{V}
$$

where, $A= \begin{cases}0^{2 / 3}\left(\frac{4 \pi N}{3}\right)^{1 / 3} & \text { for }:=1 / 2 \\ (1-0)^{2 / 3}\left(\frac{4 \pi N}{3}\right)^{1 / 3} & \text { for } \theta>1 / 2 .\end{cases}$

The density o SAT is computed us ing the liquid temperature. That is, $P_{\text {SAT }}$ is computed from the liquid temperature. $T_{C}$. using Eq. $(A .7)$. then 


$$
\rho_{\text {SAT }}^{\circ}=\frac{P_{\text {SAT }}}{(y-1) \overline{I_{V}}} \text {, }
$$

where $I_{v}$ is also computed using $T_{\ell}$. This procedure works for the case of equal phase temperatures and for the case of vapor at saturation with respect to pressure.

\section{Pipe Friction}

For one-dimensional pipe blowdown calculations it is necessary to input an appropriate two-phase pipe friction force. A standard form for this is

$$
f_{V I S}=\frac{-f}{2 D} \rho_{i}^{0} U_{i}^{2}(1-\theta)^{2} \Phi_{T P}^{2}
$$

where $D$ is the pipe diameter, $f$ the friction factor, and $\phi_{T P}$ is an appropriate friction multiplier for two-phase flow.

\section{REFERENCES}

1. Edwards, A. R. and O'Brien, T. P., "Studies of Phenomena Conncct?d with the Depressurization of Water Reactors," Jour. BNES, 9, 125 (1970).
2. Garner, R. W., "Comparative Analys is of Standard Problems, Standard Problem 1," Aerojet Nuclear Company Report, Interim Report 1-212-75-5.1, October, 1973.

3. Zuber, N. "Flow Excursions and Oscillations in Boiling Two-Phase Flow Systems with Heat Addition," Sym. Two-Phase Flow Dynamic.s, E.U.R. 4288e, 1071 (1967).

4. Edwards, A. R. and Mather, D. J., "Some UK Studies Related to the Loss of Coolant Accident," Proc. Topical Meeting WRS, Salt Lake City, Utah" 26-28 March (1973).

5. Chisholm, D., "A Theoretical Basis for the Lockhart-Martinelli Correlation for Two-Phase Flow," J. Heat Mass Transfer, 10, 1767 (1967).

6. Harlow, F. H. and Amsden, A. A., "Numerical Calculations of Multiphase Fluid Flow," J. Comp. Phys., 17, 19 (1975): Amsden, A. A. and Harlow, F. H., "KACHINA: An Eulerian Computer Program for Multifield Fluid Flows," Los Alamos Scientific Laboratory Report LA-5680 (1974).

7. Lathrop, K. D., "Quarterly Report: Transport Theory, Reactor Theory, and Reactor Safety, Jan 1 through March 31, 1975", Los Aiamos Scientific Laboratory Report LA-5964-PR (1975). 